\title{
Prognostic Significance of Thyroid Hormone For Prolonged Mechanical Ventilation In Critically III Patients With Cardiac Surgery
}

\author{
Xiao Shen \\ Nanjing Medical University \\ Jiakui Sun \\ Nanjing Medical University \\ Liang Hong \\ Nanjing Medical University \\ Xiaochun Song \\ Nanjing Medical University \\ Cui Zhang \\ Nanjing Medical University \\ Ying Liu \\ Nanjing Medical University \\ Han Liu \\ Nanjing Medical University \\ Xinwei Mu ( $\sim$ njdrmxw2012@163.com ) \\ Nanjing Medical University
}

\section{Research Article}

Keywords: prolonged mechanical ventilation, triiodothyronine, non-thyroidal illness syndrome, cardiac surgery

Posted Date: November 15th, 2021

DOI: https://doi.org/10.21203/rs.3.rs-1029226/v1

License: (c) (1) This work is licensed under a Creative Commons Attribution 4.0 International License. Read Full License 


\section{Abstract}

Background: This study aimed to examine the correlation between thyroid hormone and prolonged mechanical ventilation (MV) in the adult critically ill patients having undergone cardiac surgery.

Methods: The present study refers to a retrospective, cohort study that was conducted at Cardiovascular Intensive Care Unit (CVICU) of Nanjing First Hospital from March 2019 to December 2020. Patients receiving cardiac surgery and admitted to the center of the authors in the study period were screen for a potential inclusion. Demographic information, thyroid hormone and other laboratory measurements and outcome variables were recorded for analyses. Prolonged MV was defined as the duration of MV after cardiac surgery longer than 5 days. Thyroid hormones were assessed for the prognostic significance for prolonged MV.

Results: On the whole, 118 patients having undergone cardiac surgery were included and analyzed in this study. Patients fell to the control $(n=64)$ and the prolonged MV group $(n=54)$ by complying with the duration of MV after cardiac surgery. The median total triiodothyronine (TT3) and free triiodothyronine (FT3) were $1.03 \mathrm{nmol} / \mathrm{L}$ and $3.52 \mathrm{pmol} / \mathrm{L}$ in the prolonged MV group before cardiac surgery, significantly lower than $1.23 \mathrm{nmol} / \mathrm{L}(P=0.005)$ and $3.87 \mathrm{pmol} / \mathrm{L}$, respectively in the control $(P=0.038)$. multivariate logistic regression analysis indicated that TT3 before surgery (pre-op TT3) had a good prognostic significance for prolonged MV (OR: 0.049, $\mathrm{P}=0.012)$.

Conclusions: This study concluded that decreased triiodothyronine (T3) could be common in the cardiac patients with prolonged MV, and it would be further reduced after patients undergoing cardiac surgery. Besides, decreased T3 before surgery could act as an effective predictor for prolonged MV after cardiac surgery.

\section{Introduction}

Low triiodothyronine (T3) syndrome, i.e., non-thyroidal illness syndrome (NTIS), has been the most common abnormality of thyroid hormone in critically ill hospitalized patients[1]. Physiologically, reduced serum T3 levels refers to the initial response of the body to acute stress to fight against catabolism[2]. However, during prolonged critical illness, the normal response of the hypothalamus-pituitary-thyroid (HPT) axis can alter and contribute to low levels of T3 and thyroid-stimulating hormone (TSH), characterized as NTIS[3]. The correlation between NTIS and increased mortality in critically ill patients with sepsis and other diseases has been recently confirmed[4].

The NTIS has been demonstrated to occur in adult and pediatric patients having undergone cardiac surgery. Existing studies indicated that reductions in T3 was observed in patients undergoing cardiac surgery with or without cardiopulmonary bypass (CPB) [1]. Moreover, low T3 was indicated as a strong predictor for mortality in heart disease patients [5]. However, most studies were conducted in the population of pediatric patients. There have been rare studies in adult patients having undergone cardiac surgery. 
Since thyroid hormone is critical to muscle function, this study aimed to explore the correlation between thyroid hormone and prolonged mechanical ventilation (MV) in the adult critically ill patients having undergone cardiac surgery.

\section{Material And Methods}

\section{Patients}

The present study is a retrospective, cohort study that was conducted at an urban, tertiary care, Cardiovascular Intensive Care Unit (CVICU) of Nanjing First Hospital, a Teaching Medical College Hospital in China. Patients receiving cardiac surgery and admitted to the center of the authors from March 2019 to December 2020 were screened for a potential inclusion. The data of the patients were screened and collected from the electronic medical record (EMR) databases. All the study protocol was performed in accordance with the Declaration of Helsinki and was approved by Ethics Committee of Nanjing First Hospital, Nanjing Medical University (KY20170811-03).

The inclusion criteria of this study included: (1) adult patients with cardiac disease who had undergone cardiac surgery with CPB, (2) patients admitted to the center of the authors immediately after surgery, (3) available assessments of thyroid hormone before and $24 \mathrm{~h}$ after cardiac surgery, and (4) patients receiving MV for over $48 \mathrm{~h}$ after cardiac surgery. Patients who were pregnant, with known thyroid diseases and abnormal thyroid gland on palpation and other examinations (e.g., enlarged thyroid and thyroid nodules), or on hormonal therapy were excluded here.

\section{Data collection}

Demographic information was recorded for further analyses (e.g., gender, age, body mass index (BMI), Acute Physiology and Chronic Health Evaluation II (APACHE II) score, EuroSCORE and co-morbidities as well as thyroid hormone and other chemical data). In addition, types of operation and operation time were collected. Moreover, outcome variables (e.g., hospital mortality, time of MV, length of hospital stay and ICU stay) were recorded for further comparison. Prolonged MV was defined as the duration of MV after cardiac surgery longer than 5 days.

\section{Laboratory measurements}

To conduct thyroid hormone analysis, total T3 (TT3), free T3 (FT3), total thyroxine (TT4), free thyronine (FT4) and TSH were determined from blood samples of the patients before and $24 \mathrm{~h}$ after cardiac surgery. Thyroid hormone was detected with Chemiluminescence immunoassay instrument (MAGLUMI 2000, Snibe Diagnostic, China). In addition, the reference values of the hospital of the authors included: TT3: 0.98-2.33nmol/L, TT4: 62.68-150.84nmol/L, FT3: $2.43-6.01 \mathrm{pmol} / \mathrm{L}, \mathrm{FT} 4:$ : $9.00-19.00 \mathrm{pmol} / \mathrm{L}$ and TSH: $0.35-4.94 \mathrm{mIU} / \mathrm{L}$. Lactate was obtained from arterial blood gas with ICU blood-gas analyzer (NOVA CCX Blood Gas Analyzer, USA), and white blood cell (WBC) counts were determined from blood routine test performed in the central laboratory of the hospital of the authors with the use of automatic blood cell analyzer (COULTER LH 750, Beckman Coulter, USA). Biochemical analysis, involving total protein, 
albumin, aspartate aminotransferase (ALT), aspartate aminotransferase (AST), total bilirubin and creatinine, was conducted in the central laboratory of the hospital of the authors by applying an Aeroset analyzer (Hitachi 7180 Automatic Biochemical Analyzer, Japan). The serum level of $\mathrm{N}$-terminal pro brain natriuretic peptide (NT-proBNP) was identified with rapid diagnostic cassette and Immunoquantitative analyzer (FIA8000, Getein Biotech, China).

\section{Statistical analysis}

SPSS 22.0 statistical software package (IBM Analytics, USA) was employed for the statistical analysis, and $P<0.05$ was considered with statistical significance. Continuous variables were expressed as median plus interquartile range (IQR), and categorical variables were expressed as frequency plus percentage. The differences between groups were assessed by performing student's $t$ test for continuous variables with normality distribution and Mann-Whitney $U$ test for continuous variables without normality distribution. The differences between groups for categorical variables were compared by performing Chisquare test.

Correlations between variables and prolonged MV were assessed by conducting logistic regression analysis. Variables with statistical significance in the univariate logistic regression were covered in the multivariate logistic regression. Moreover, receiver operating characteristic (ROC) curve was plotted to assess the prognostic ability of the variable for prolonged MV. Next, univariate and multivariate linear regression analysis were conducted to identify the correlations between variables and time of MV. Likewise, in-depth multivariate linear regression only involved the variables showing statistical significance in the univariate analysis.

\section{Results}

On the whole, 1896 patients admitted to the center of the authors and having undergone cardiac surgery were screened, and 1778 patients were excluded (Fig. 1), leaving 118 patients included and analyzed in this study. Patients fell to the control $(n=64)$ and the prolonged MV group $(n=54)$ by complying with the duration of MV after cardiac surgery. Prolonged MV was defined as time of MV longer than 5 days after cardiac surgery.

Table 1 lists the baseline characteristics exhibited by the patients. The patients had the overall mortality of $18.6 \%$. To be specific, 11 patients died of septic shock and multiple organ failure, 8 patients died of malignant arrhythmia and cardiac arrest, 2 patients died of heart failure and multiple organ failure, and 1 patient died of gastrointestinal hemorrhage. Compared with the control, the prolonged MV group had a markedly longer length of hospital stay (27 days [21, 37] vs. 22 days [17, 28], $P=0.002)$ and ICU stay (12 days $[8,19]$ vs. 5 days $[4,10], P<0.001)$, as well as a prolonged duration of MV $(8$ days $[5,10]$ vs. 3 days $[3,4], P<0.001)$. No statistically significant difference was identified in the common clinical parameters (e.g., gender, age, BMI, APACHE II score and euroSCORE) between the control and the prolonged MV group. The main types of cardiac surgery consisted of aortic surgery, isolated valve surgery and combined surgery of coronary artery bypass grafting (CABG) and valve surgery in prolonged MV patients. 
The proportion of patients having undergone aortic surgery in the prolonged MV group exceeded that in the control (28 [51.8\%] vs. 22 [34.4\%], $P=0.056)$, though without statistically difference. The two groups had similar incidences of co-morbidities except chronic kidney disease, higher than that of the control (4 $[6.2 \%]$ vs. $0[0 \%], P=0.025)$. The left ventricular ejection fraction (LVEF) of the patients before cardiac surgery was comparable in the two groups, as well as the operation time. 
Table 1

Baseline characteristics of the patients underwent cardiac surgery

\begin{tabular}{|c|c|c|c|c|}
\hline Variable & $\begin{array}{l}\text { Control group } \\
(n=64)\end{array}$ & $\begin{array}{l}\text { Prolonged MV group } \\
(n=54)\end{array}$ & $\begin{array}{l}\text { Total } \\
(n=118)\end{array}$ & $\begin{array}{l}P \\
\text { value }\end{array}$ \\
\hline Male sex, n (\%) & $36(56.2)$ & $35(64.8)$ & $72(61.0 \%)$ & 0.344 \\
\hline Age, y & $66(54,71)$ & $66(55,72)$ & $66(54,72)$ & 0.906 \\
\hline BMI & $23.9(21.1,26.9)$ & $24.8(21.0,27.6)$ & $\begin{array}{l}24.1(21.1, \\
27.6)\end{array}$ & 0.774 \\
\hline APACHE II score & $15(13,18)$ & $15(12,18)$ & $15(12,18)$ & 0.590 \\
\hline EuroSCORE & $7(5,8)$ & $6(5,8)$ & $7(5,8)$ & 0.930 \\
\hline Length of hospital stay, $d$ & $22(17,28)$ & $27(21,37)$ & $25(19,32)$ & 0.002 \\
\hline Length of ICU stay, d & $5(4,10)$ & $12(8,19)$ & $8(5,13)$ & $<0.001$ \\
\hline $\begin{array}{l}\text { Time of mechanical } \\
\text { ventilation, } d\end{array}$ & $3(3,4)$ & $8(5,10)$ & $4(3,7)$ & $<0.001$ \\
\hline Mortality, n (\%) & $11(17.2)$ & $10(18.5)$ & $22(18.6 \%)$ & 0.851 \\
\hline \multicolumn{5}{|l|}{ Type of operation, n (\%) } \\
\hline Isolated valve surgery & $16(25.0)$ & $15(27.8)$ & $31(26.3)$ & 0.733 \\
\hline Isolated CABG & $9(14.1)$ & $3(5.6)$ & $12(10.2)$ & 0.223 \\
\hline $\begin{array}{l}\text { Combined CABG and valve } \\
\text { surgery }\end{array}$ & $13(20.3)$ & $6(11.1)$ & $19(16.1)$ & 0.175 \\
\hline Aortic surgery & $22(34.4)$ & $28(51.8)$ & $50(42.4)$ & 0.056 \\
\hline Other surgery & $4(6.2)$ & $2(3.7)$ & $6(5.1)$ & 0.836 \\
\hline \multicolumn{5}{|l|}{$\begin{array}{l}\text { Co-morbidities } \\
\text {, n (\%) }\end{array}$} \\
\hline Coronary heart disease & $28(43.8)$ & $15(27.8)$ & $42(35.6)$ & 0.072 \\
\hline Hypertension & $38(59.4)$ & $34(63.0)$ & 73 (61.9) & 0.691 \\
\hline Diabetes mellitus & $14(21.9)$ & $9(16.7)$ & $23(19.5)$ & 0.477 \\
\hline Arterial fibrillation & $15(23.4)$ & $6(11.1)$ & $20(16.9)$ & 0.081 \\
\hline Stroke & 7 (10.9) & $3(5.6)$ & $10(8.5)$ & 0.475 \\
\hline Chronic kidney disease & $4(6.2)$ & $0(0)$ & $4(3.4)$ & 0.025 \\
\hline
\end{tabular}

MV: Mechanical ventilation, BMl: Body mass index, APACHE II: Acute Physiology and Chronic Health Evaluation II, ICU: Intensive Care Unit, CABG: Coronary artery bypass grafting, LVEF: Left ventricular ejection fraction. 


\begin{tabular}{|lllll|}
\hline Variable & $\begin{array}{l}\text { Control group } \\
(\mathbf{n = 6 4 )}\end{array}$ & $\begin{array}{l}\text { Prolonged MV group } \\
(\mathbf{n = 5 4 )}\end{array}$ & $\begin{array}{l}\text { Total } \\
(\mathbf{n = 1 1 8})\end{array}$ & $\begin{array}{l}\boldsymbol{P} \\
\text { value }\end{array}$ \\
\hline LVEF, \% & $49(40,62)$ & $57(46,61)$ & $53(40,61)$ & 0.240 \\
\hline Operation time, min & $350(275,405)$ & $375(290,446)$ & $\begin{array}{l}355(280, \\
440)\end{array}$ & 0.179 \\
\hline & & & \\
\hline
\end{tabular}

Table 2 lists the levels of thyroid hormones of the patients before and after cardiac surgery. The median TT3 and FT3 reached $1.03(0.86,1.17) \mathrm{nmol} / \mathrm{L}$ and $3.52(3.11,3.77) \mathrm{pmol} / \mathrm{L}$ in the prolonged $\mathrm{MV}$ group before cardiac surgery, significantly lower than $1.23(1.02,1.54) \mathrm{nmol} / \mathrm{L}(P=0.005)$ and $3.87(3.26,4.34)$ $\mathrm{pmol} / \mathrm{L}$, respectively in the control $(P=0.038$, Fig. 2$)$. No significant differences were identified in the serum levels of TT4, FT4 and TSH before cardiac surgery in the patients of the two groups. The serum levels of thyroid hormones had an overall decrease after cardiac surgery when compared with those before surgery (Fig. 2). The median FT3 after cardiac surgery was $2.30(1.64,2.56) \mathrm{pmol} / \mathrm{L}$ in the prolonged MV group, markedly lower than $2.4(2.30,2.75) \mathrm{pmol} / \mathrm{L}$ in the control $(P=0.03$, Fig. 2$)$. However, no significant differences were reported in other indexes of thyroid hormones (e.g., TT3, TT4, FT4 and $\mathrm{TSH}$ ) in the two groups after cardiac surgery. 
Table 2

Serum concentration of thyroid hormones before and after cardiac surgery

\begin{tabular}{|llll|}
\hline Variable & Control group $(\mathbf{n}=64)$ & Prolonged MV group $(\mathbf{n}=54)$ & Pvalue \\
\hline Pre-operation & & & \\
\hline TT3, noml/L & $1.28(1.02,1.54)$ & $1.03(0.86,1.17)$ & 0.005 \\
\hline TT4, nmol/L & $98.79(87.33,111.19)$ & $93.93(79.34,106.36)$ & 0.153 \\
\hline FT3, pmol/L & $3.87(3.26,4.34)$ & $3.52(3.11,3.77)$ & 0.038 \\
\hline FT4, pmol/L & $13.4(11.7,15.2)$ & $12.72(11.02,13.68)$ & 0.098 \\
\hline TSH, mlU/L & $2.20(1.50,3.75)$ & $1.68(0.68,3.81)$ & 0.601 \\
\hline Post-operation & & & 0.239 \\
\hline TT3, nmol/L & $0.66(0.61,0.76)$ & $0.61(0.54,0.76)$ & 0.298 \\
\hline TT4, nmol/L & $74.38(54.87,89.50)$ & $70.33(50.46,81.21)$ & 0.030 \\
\hline FT3, pmol/L & $2.40(2.30,2.75)$ & $2.30(1.64,2.56)$ & 0.141 \\
\hline FT4, pmol/L & $12.86(10.93,13.96)$ & $11.16(8.66,13.02)$ & 0.582 \\
\hline TSH, mlU/L & $1.23(0.09,2.46)$ & $0.82(0.18,2.43)$ & \\
\hline $\begin{array}{l}\text { MV: Mechanical ventilation, TT3: Total triiodothyronine, FT3: Free triiodothyronine, TT4: Total } \\
\text { thyroxine, FT4: Free thyronine, TSH: Thyroid-stimulating hormone. }\end{array}$ & \\
\hline
\end{tabular}

Table 3 lists other laboratory parameters of the control and the prolonged MV group. NT-proBNP, total protein, albumin, AST, ALT, total bilirubin, creatinine, WBC as well as lactate before cardiac surgery were not different between the control and the prolonged MV group. No differences were identified in the mentioned laboratory parameters after cardiac surgery between the two groups either. 
Table 3

Laboratory parameters of the patients before and after cardiac surgery

\begin{tabular}{|c|c|c|c|}
\hline Variable & Control group $(n=64)$ & Prolonged MV group $(n=54)$ & $P$ value \\
\hline \multicolumn{4}{|l|}{ Pre-operation } \\
\hline NT-proBNP, pg/ml & $2143.3(325.2,5603.1)$ & $2091.2(557.4,7506.3)$ & 0.885 \\
\hline Total protein, $\mathrm{g} / \mathrm{L}$ & $65.8(63.2,69.1)$ & $64.6(61.0,67.7)$ & 0.675 \\
\hline Albumin, g/L & $39.6(37.1,40.9)$ & $38.9(37.1,41.6)$ & 0.413 \\
\hline AST, U/L & $21.0(16.0,30.0)$ & $24.5(18.0,30.2)$ & 0.358 \\
\hline $\mathrm{ALT}, \mathrm{U} / \mathrm{L}$ & $17.0(13.0,27.0)$ & $15.0(10.0,23.2)$ & 0.267 \\
\hline Total bilirubin, umol/L & $13.5(9.0,23.9)$ & $12.3(9.4,18.2)$ & 0.273 \\
\hline Creatinine, umol/L & $76.5(62.6,92.6)$ & $77.0(64.9,101.0)$ & 0.527 \\
\hline WBC, $\times 10^{\wedge} 9 / L$ & $6.8(5.0,8.8)$ & $7.4(6.2,11.8)$ & 0.055 \\
\hline Lac, mmol/L & $1.4(0.9,2.2)$ & $1.3(0.8,2.3)$ & 0.426 \\
\hline \multicolumn{4}{|l|}{ Post-operation } \\
\hline Total protein & $49.0(46.5,54.3)$ & $50.2(44.7,55.3)$ & 0.892 \\
\hline Albumin & $33.7(31.8,36.9)$ & $33.1(30.6,37.1)$ & 0.944 \\
\hline AST & $63.0(52.0,99.0)$ & $43.0(36.5,66.0)$ & 0.620 \\
\hline ALT & $20.0(12.0,30.0)$ & $20.5(12.2,28.8)$ & 0.351 \\
\hline Total bilirubin & $18.8(10.8,29.6)$ & $17.0(13.4,29.6)$ & 0.472 \\
\hline Creatinine & $85.5(65.0,110.4)$ & $81.7(65.9,117.1)$ & 0.426 \\
\hline WBC & $10.4(7.7,16.7)$ & $11.6(7.7,15.2)$ & 0.465 \\
\hline PCT & $1.6(0.1,7.1)$ & $0.7(0.2,1.9)$ & 0.230 \\
\hline Lac & $2.8(1.7,5.5)$ & $3.3(1.6,6.0)$ & 0.393 \\
\hline
\end{tabular}

Subsequently, logistic regression analysis was conducted to determine the prognostic significance of the respective variable for prolonged $\mathrm{MV}$. Univariate logistic regression indicated the correlations between prolonged MV and TT3 (pre-op TT3, Odds Ratio [OR]: 0.045, 95\% confidence interval [Cl]: 0.004-0.470, $P=0.010$ ) and FT3 (pre-op FT3, OR: $0.401,95 \%$ Cl: $0.163-0.987, P=0.047$ ) before cardiac surgery (Table 4). According to in-depth multiple stepwise logistic regression analysis by adopting the mentioned variables, significant correlations were found between prolonged MV and pre-op TT3 (OR: 0.049, 95\% Cl: 0.005- 
$0.523, P=0.012$, Table 5). The area under the ROC curve (AUROC) reached 0.73 (95\% Cl: $0.593-0.868$, $P=0.006$ ) for pre-op TT3, indicating high prognostic significance for prolonged MV. The specificity and sensitivity of pre-op TT3 for prolonged MV reached $84.2 \%$ and $60.6 \%$, respectively, with a cut-off value for of $1.255 \mathrm{nmol} / \mathrm{L}$. 
Table 4

Logistic regression for baseline and laboratory variables to predict prolonged MV

\begin{tabular}{|c|c|c|c|}
\hline Variable & OR & $95 \% \mathrm{Cl}$ & $P$ value \\
\hline Male sex & 1.382 & $0.653-2.922$ & 0.398 \\
\hline Age & 0.998 & $0.970-1.028$ & 0.905 \\
\hline BMI & 1.012 & 0.933-1.097 & 0.772 \\
\hline APACHE II score & 1.020 & $0.949-1.096$ & 0.587 \\
\hline EuroSCORE & 1.007 & $0.871-1.164$ & 0.930 \\
\hline LVEF & 10.311 & $0.210-505.667$ & 0.240 \\
\hline Operation time & 1.002 & $0.999-1.006$ & 0.180 \\
\hline \multicolumn{4}{|l|}{ Pre-operation } \\
\hline NT-proBNP & 1.000 & $1.000-1.000$ & 0.882 \\
\hline Total protein & 0.981 & $0.901-1.070$ & 0.671 \\
\hline Albumin & 1.030 & 0.958-1.107 & 0.425 \\
\hline AST & 1.001 & $0.998-1.004$ & 0.474 \\
\hline ALT & 0.984 & 0.953-1.015 & 0.312 \\
\hline Total bilirubin & 0.973 & $0.927-1.022$ & 0.276 \\
\hline Creatinine & 0.998 & $0.993-1.004$ & 0.529 \\
\hline WBC & 1.118 & $0.999-1.252$ & 0.053 \\
\hline Lac & 0.881 & $0.636-1.219$ & 0.443 \\
\hline TT3 & 0.045 & $0.004-0.470$ & 0.010 \\
\hline TT4 & 0.975 & $0.942-1.010$ & 0.156 \\
\hline FT3 & 0.401 & $0.163-0.987$ & 0.047 \\
\hline FT4 & 0.763 & $0.551-1.055$ & 0.102 \\
\hline TSH & 0.931 & $0.716-1.211$ & 0.594 \\
\hline
\end{tabular}

MV: Mechanical ventilation, OR: Odds ratio, CT: Confidence interval, BMl: Body mass index, APACHE II: Acute Physiology and Chronic Health Evaluation II, LVEF: Left ventricular ejection fraction, NTproBNP: N-terminal pro brain natriuretic peptide, AST: Aspartate aminotransferase, ALT: Aspartate aminotransferase, WBC: White blood cell, Lac: Lactate, TT3: Total triiodothyronine, FT3: Free triiodothyronine, TT4: Total thyroxine, FT4: Free thyronine, TSH: Thyroid-stimulating hormone, PCT: Procalcitonin. 


\begin{tabular}{|llll|}
\hline Variable & OR & $95 \%$ Cl & P value \\
\hline Total protein & 1.003 & $0.957-1.052$ & 0.891 \\
\hline Albumin & 0.997 & $0.912-1.089$ & 0.943 \\
\hline AST & 1.001 & $0.998-1.003$ & 0.631 \\
\hline ALT & 1.001 & $0.999-1.003$ & 0.379 \\
\hline Total bilirubin & 0.991 & $0.968-1.015$ & 0.470 \\
\hline Creatinine & 0.998 & $0.992-1.003$ & 0.433 \\
\hline WBC & 0.977 & $0.917-1.041$ & 0.473 \\
\hline PCT & 0.925 & $0.791-1.080$ & 0.323 \\
\hline Lac & 1.056 & $0.932-1.196$ & 0.392 \\
\hline TT3 & 0.047 & $0.000-7.350$ & 0.236 \\
\hline TT4 & 0.981 & $0.947-1.017$ & 0.295 \\
\hline FT3 & 0.172 & $0.028-1.043$ & 0.056 \\
\hline FT4 & 0.829 & $0.643-1.068$ & 0.147 \\
\hline TSH & 1.032 & $0.918-1.161$ & 0.595 \\
\hline $\begin{array}{l}\text { MV: Mechanical ventilation, OR: Odds ratio, CT: Confidence interval, BMI: Body mass index, APACHE } \\
\text { I: Acute Physiology and Chronic Health Evaluation II, LVEF: Left ventricular ejection fraction, NT- } \\
\text { aminotransferminal pro brain natriuretic peptide, AST: Aspartate aminotransferase, ALT: Aspartate } \\
\text { triiodothyronine, TT4: Total thyroxine, FT4: Free thyronine, TSH: Thyroid-stimulating hormone, PCT: } \\
\text { Procalcitonin. }\end{array}$ & & \\
\hline
\end{tabular}

Table 5

Multivariate stepwise logistic regression and AUROC for baseline and laboratory variables to predict prolonged MV.

\begin{tabular}{|lcccc|}
\hline & OR $(95 \% \mathrm{Cl})$ & $P$ value & AUROC $(95 \% \mathrm{Cl})$ & $P$ value \\
\hline Pre-op TT3 & $0.049(0.005-0.523)$ & 0.012 & $0.730(0.593-0.868)$ & 0.006 \\
\hline $\begin{array}{l}\text { AUROC: The area under the receiver operating characteristic curve, OR: Odds ratio, CT: Confidence } \\
\text { interval, MV: Mechanical ventilation, pre-op TT3: Total triiodothyronine before operation. }\end{array}$ \\
\hline
\end{tabular}

In addition, the correlations between laboratory parameters and duration of MV were also assessed. As revealed from the univariate linear regression models, LVEF (OR: 8.988, 95\% Cl: 0.231 to 17.745 , $P=0.044$ ), pre-op TT3 (OR: $-3.674,95 \% \mathrm{Cl}:-6.332$ to $-1.017, P=0.008)$, FT4 after surgery (Post-op FT4, OR: $-0.652,95 \% \mathrm{Cl}:-1.270$ to $-0.035, P=0.039$ ) were significantly correlated with the duration of MV (Table 6). After the further multivariate analysis, as expected, LVEF (OR: $-13.074,95 \% \mathrm{Cl}:-20.489$ to -5.659 , $P=0.028)$, pre-op TT3 (OR: $-7.916,95 \%$ Cl: -10.352 to $-5.481, P=0.015)$ and post-op FT4 (OR: $-0.835,95 \%$ 
Cl: -1.029 to $-0.640, P=0.012)$ still showed independent and significant correlation with the duration of MV.

Table 6

Univariate and multivariate analyses of factors associated with MV time

\begin{tabular}{|c|c|c|c|c|c|c|}
\hline \multirow[b]{2}{*}{ Variable } & \multicolumn{3}{|c|}{ Univariate analysis } & \multicolumn{3}{|c|}{ Multivariate analysis } \\
\hline & OR & $95 \% \mathrm{Cl}$ & $P$ value & OR & $95 \% \mathrm{Cl}$ & $P$ value \\
\hline Age & 0.019 & -0.047 to 0.085 & 0.572 & & & \\
\hline BMI & -0.041 & -0.225 to 0.142 & 0.656 & & & \\
\hline APACHE II score & -0.020 & -0.182 to 0.142 & 0.807 & & & \\
\hline EuroSCORE & -0.235 & -0.562 to 0.091 & 0.156 & & & \\
\hline LVEF & 8.988 & 0.231 to 17.745 & 0.044 & -13.074 & -20.489 to -5.659 & 0.028 \\
\hline Operation time & 0.002 & -0.006 to 0.010 & 0.572 & & & \\
\hline Pre-op TT3 & -3.674 & -6.332 to -1.017 & 0.008 & -7.916 & -10.352 to -5.481 & 0.015 \\
\hline Pre-op TT4 & -0.041 & -0.092 to 0.011 & 0.118 & & & \\
\hline Pre-op FT3 & -0.694 & -1.825 to 0.436 & 0.223 & & & \\
\hline Pre-op FT4 & -0.401 & -0.859 to 0.056 & 0.084 & & & \\
\hline Pre-op TSH & -0.061 & -0.451 to 0.329 & 0.755 & & & \\
\hline Post-op TT3 & -13.129 & -26.618 to 0.361 & 0.056 & & & \\
\hline Post-op TT4 & -0.086 & -0.182 to 0.010 & 0.078 & & & \\
\hline Post-op FT3 & -0.762 & -5.178 to 3.654 & 0.728 & & & \\
\hline Post-op FT4 & -0.652 & -1.270 to -0.035 & 0.039 & -0.835 & -1.029 to -0.640 & 0.012 \\
\hline Post-op TSH & 0.088 & -0.166 to 0.342 & 0.487 & & & \\
\hline $\begin{array}{l}\text { MV: Mechanical } \\
\text { Il: Acute Physiolo } \\
\text { TT3: Total triiodo } \\
\text { op TT4: Total thy } \\
\text { Thyroid-stimulati } \\
\text { Post-op FT3: Free } \\
\text { op FT4: Free thyre }\end{array}$ & $\begin{array}{l}\text { entilation, } \\
\text { y and Chr } \\
\text { hyronine } \\
\text { oxine bef } \\
\text { g hormon } \\
\text { triiodothy } \\
\text { nine after }\end{array}$ & $\begin{array}{l}\text { R: Odds ratio, CT: } \\
\text { nic Health Evaluati } \\
\text { efore operation, Pre } \\
\text { e operation, Pre-op } \\
\text { before operation, } \\
\text { nine after operatio } \\
\text { peration, Post-op T }\end{array}$ & $\begin{array}{l}\text { onfidence } \\
\text { 1 II, LVEF: } \\
\text { p FT3: Fre } \\
\text { T4: Free tl } \\
\text { st-op TT3 } \\
\text { Post-op T } \\
\text { H: Thyroi }\end{array}$ & $\begin{array}{l}\text { nterval, BN } \\
\text {-eft ventric } \\
\text { e triiodothy } \\
\text { yronine be } \\
\text { Total triio } \\
\text { T4: Total tl }\end{array}$ & $\begin{array}{l}\text { : Body mass index, } \\
\text { lar ejection fraction } \\
\text { onine before operat } \\
\text { ore operation, Pre-o } \\
\text { othyronine after op€ } \\
\text { yroxine after operat } \\
\text { hormone after ope }\end{array}$ & $\begin{array}{l}\text { PACHE } \\
\text { Pre-op } \\
\text { on, Pre- } \\
\text { TSH: } \\
\text { ation, } \\
\text { n, Post- } \\
\text { ation. }\end{array}$ \\
\hline
\end{tabular}

\section{Discussion}

\section{Key findings}


A retrospective, cohort study was conducted to assess the prognostic significance of thyroid hormone for prolonged MV in critically ill patients having undergone cardiac surgery. As revealed from the results of this study, serum levels of thyroid hormone were down-regulated significantly in the cardiac patients having undergone cardiac surgery. Besides, prolonged MV patients after cardiac surgery had markedly lower level of TT3 before surgery. Furthermore, TT3 before surgery, significantly correlated with the duration of $\mathrm{MV}$, acted as an effective predictor for prolonged MV in patients having undergone cardiac surgery.

\section{Relationship to previous studies}

NTIS refers to a common endocrine disorder in critically ill patients, which has been correlated with various manifestations in the ICU. Hypothyroidism might be critical to the persistent spectrum of symptoms identified in the critically ill patients. Considerable studies confirmed the prognostic significance of NTIS for mortality in the critically ill patients[4, 6-8], whereas the studies largely concentrated on the critically ill patients with internal medical disease (e.g., sepsis and septic shock). The prognostic significance of NTIS or T3 in surgical critically ill patients remains not known. In this study, a correlation was not identified between T3 and the mortality in the patients having undergone cardiac surgery, primarily attributed to the heterogeneity of study population.

The critical primary condition, severe surgical trauma and short-term postoperative adverse events of the patients after cardiac surgery seriously limited the surgical efficacy and prognosis of patients, i.e., the major problems to be urgently solved by the clinical physicians at present. Patients with cardiac disease suffer from long-term heart disease, resulting in long-term stress state attributed to the disease, often complicated with NTIS even before cardiac surgery. Furthermore, the level of thyroid hormone would further decrease after cardiac, thereby seriously affecting the prognosis of patients.

NTIS is traditionally recognized as a self-protection mechanism that down-regulates the overall metabolism to conserve energy under stress. With the gradual recovery of body injury, the symptoms of NTIS will be mitigated, so intervention will not be required. However, when the stress state or critical illness persists, NTIS will adversely affect the recovery of the body, thereby resulting in overcorrection. Thus, positive intervention may improve the prognosis.

Several studies demonstrated the beneficial effect of thyroid hormone replacement in the patients having undergone cardiac surgery. A prospective study performed by Zhang et al.[9] revealed that the incidence of postoperative NTIS could be reduced and the myocardial ischemia-reperfusion injury in pediatric patients could be protected by taking oral thyroid hormone $0.4 \mathrm{mg} / \mathrm{kg}$ for 4 consecutive days before cardiac surgery. The study by Marwali et al. [10] also confirmed the promoting effect of thyroid hormone replacement in pediatric patients having undergone cardiac surgery. They indicated that the incidence of postoperative low cardiac output syndrome could be down-regulated through the administration of 1 $\mathrm{mg} / \mathrm{kg}$ thyroid hormone every $6 \mathrm{~h}$ after surgery for patients undergoing cardiopulmonary bypass. In a prospective, multicenter, randomized, double-blind controlled study by Portman et al.[11], intravenously administered T3 effectively could up-regulate serum levels of FT3 in patients having undergone coronary 
artery bypass grafting for congenital heart disease without significant adverse effects and improve the cardiac function significantly. However, as suggested from a meta-analysis by Flores et al.[12], T3 treatment after cardiopulmonary bypass could not reduce mortality and duration of MV and ICU stay, as well as improving cardiac function. Likewise, two studies in patients with $\operatorname{CABG}[13,14]$ showed no beneficial effect of thyroid hormone replacement for the prognosis. Besides, most of the existing studies were conducted in pediatric patients having undergone cardiac surgery. Evidences in adult cardiac patients were insufficient. At present, no evidence-based consensus or guideline advocates thyroid hormone replacement in the patients having undergone cardiac surgery. Further prospective studies might be required to identify the effect of thyroid hormone replacement in adult patients having undergone cardiac surgery.

Thyroid hormone is important for skeletal muscle function, as a series of genes expressed in muscle are regulated by T3. Depending on the type of disease (e.g., acute inflammation or sepsis) and stage (e.g., acute or prolonged phase), thyroid hormone signaling varies in skeletal muscle tissue during disease. Accordingly, hypothyroidism would adversely affect respiratory function by blunting the response of the body to hypercapnia and hypoxia and impairing skeletal muscle and diaphragm function. A prospective cohort study by Yasar et al.[15] suggested NTIS as an independent predictor for prolonged MV in patients with chronic obstructive pulmonary disease (COPD), complying with the results of this study. Another study by Datta et al.[16] confirmed the significance of hypothyroidism prolonged MV in the 140 patients with underlying respiratory failure. According to a case report by Kumar et al.[3], intravenous levothyroxine reversed the prolonged shock of uncertain etiology and difficulty weaning from MV in critically ill patients, thereby implying that low levels of thyroid hormone might be part of the cause for prolonged MV.

\section{Study implications}

As impacted by the characteristics of the primary diseases and surgical intervention, complications after surgery are commonly the primary concerns for the patients having undergone cardiac surgery. Though numerous studies confirmed the prognostic significance of NTIS in medical critically ill patients, existing studies on adult patients having undergone cardiac surgery have been rare. Also, the exact effect of postoperative thyroid hormone supplementation remains controversial. This study demonstrated the prognostic significance of T3 before surgery for prolonged MV after cardiac surgery, which might help prove the necessity of thyroid hormone therapy in the patients having undergone cardiac surgery. However, the exact population requiring thyroid hormone therapy and the time of intervention may still be verified by large-scale, multi-center and high-quality clinical studies.

\section{Limitations}

This study has several limitations. First, the patients with MV for over $48 \mathrm{~h}$ after cardiac surgery were only included, and considerable patients having undergone cardiac surgery were excluded. In this way, the result in this study may not be applicable to all the patients having undergone cardiac surgery. Second, since this study is a retrospective study, it might cause selection biases. Third, as impacted by the 
restriction of this retrospective study, the effect of thyroid hormone supplementation on the prognosis and prolonged MV was not assessed here.

\section{Conclusions}

This study investigated the prognostic significance of $\mathrm{T} 3$ for prolonged MV in patients having undergone cardiac surgery. As revealed from this study, decreased T3 could be common in the cardiac patients with prolonged MV before surgery, and it would be further reduced after patients undergoing cardiac surgery. Decreased T3 before surgery was an effective predictor for prolonged MV after cardiac surgery, thereby demonstrating that thyroid hormone therapy might be profitable in the mentioned patients.

\section{Abbreviations}

MV: mechanical ventilation

T3: triiodothyronine

NTIS: non-thyroidal illness syndrome

HPT: hypothalamus-pituitary-thyroid

TSH: thyroid-stimulating hormone

CPB: cardiopulmonary bypass

CVICU: Cardiovascular Intensive Care Unit

BMI: body mass index

APACHE II: Acute Physiology and Chronic Health Evaluation II

ICU: Intensive Care Unit

TT3: total triiodothyronine

FT3: free triiodothyronine

TT4: total thyroxine

FT4: free thyroxine

WBC: white blood cell

ALT: aspartate aminotransferase

AST: aspartate aminotransferase 
IQR: interquartile range

ROC: receiver operating characteristic

CABG: coronary artery bypass grafting

LVEF: left ventricular ejection fraction

OR: Odds Ratio

Cl: confidence interval

Pre-op TT3: Total triiodothyronine before operation

Pre-op FT3: Free triiodothyronine before operation

Pre-op TT4: Total thyroxine before operation

Pre-op FT4: Free thyronine before operation

Pre-op TSH: Thyroid-stimulating hormone before operation

Post-op TT3: Total triiodothyronine after operation

Post-op FT3: Free triiodothyronine after operation

Post-op TT4: Total thyroxine after operation

Post-op FT4: Free thyronine after operation

Post-op TSH: Thyroid-stimulating hormone after operation

AUROC: area under the receiver operating characteristic curve

COPD: chronic obstructive pulmonary disease

\section{Declarations}

Ethics approval and consent to participate: For the conduction and data collection of the study, the approval was gained from the institutional Ethics Committee of Nanjing First Hospital.

Consent for publication: Not applicable.

Availability of data and materials: The datasets generated and/or analysed during the current study are not publicly available due to the protection for the patients' privacy but are available from the corresponding author on reasonable request. 
Competing interestsロThe authors declare that they have no competing interests.

Funding: This study was supported by National Natural Science Foundation of China (Grant No.: 81801891 and 81701881) and Natural Science Foundation of Jiangsu Province, China (Grant No.: BK20180134). The funding agency had no role in study design, the collection of data, in the interpretation of data, in the writing of the article, or in the decision to submit the article for publication.

Authors' contributions: XS and JKS contributed to design, data acquisition, statistical analysis and drafted the manuscript. LH and XCS contributed to data acquisition, data analysis and presentation. YL and HL contributed to data acquisition and data analysis. CZ and XWM contributed to study control, study design and manuscript drafting. XWM contributed to manuscript drafting and revision. XS and JKS contributed equally to the paper. All authors have read and approved the final manuscript.

Acknowledgements: Not applicable.

\section{References}

1. Ranasinghe AM, Bonser RS: Thyroid hormone in cardiac surgery. Vascul Pharmacol 2010, 52(34):131-137.

2. Warner $\mathrm{MH}$, Beckett $\mathrm{GJ}$ : Mechanisms behind the non-thyroidal illness syndrome: an update. The Journal of endocrinology 2010, 205(1):1-13.

3. Kumar E, McCurdy MT, Koch CA, Hamadah A, Fulop T, Gharaibeh KA: Impairment of Thyroid Function in Critically III Patients in the Intensive Care Units. Am J Med Sci 2018, 355(3):281-285.

4. Padhi R, Kabi S, Panda BN, Jagati S: Prognostic significance of nonthyroidal illness syndrome in critically ill adult patients with sepsis. International journal of critical illness and injury science 2018, 8(3):165-172.

5. Gerdes AM, lervasi G: Thyroid replacement therapy and heart failure. Circulation 2010, 122(4):385393.

6. Qari FA: Thyroid function status and its impact on clinical outcome in patients admitted to critical care. Pakistan journal of medical sciences 2015, 31(4):915-919.

7. Plikat K, Langgartner J, Buettner R, Bollheimer LC, Woenckhaus U, Scholmerich J, Wrede CE: Frequency and outcome of patients with nonthyroidal illness syndrome in a medical intensive care unit. Metabolism: clinical and experimental 2007, 56(2):239-244.

8. Angelousi AG, Karageorgopoulos DE, Kapaskelis AM, Falagas ME: Association between thyroid function tests at baseline and the outcome of patients with sepsis or septic shock: a systematic review. Eur J Endocrinol 2011, 164(2):147-155.

9. Zhang JQ, Yang QY, Xue FS, Zhang W, Yang GZ, Liao X, Meng FM: Preoperative oral thyroid hormones to prevent euthyroid sick syndrome and attenuate myocardial ischemia-reperfusion injury after cardiac surgery with cardiopulmonary bypass in children: A randomized, double-blind, placebocontrolled trial. Medicine 2018, 97(36):e12100. 
10. Marwali EM, Caesa P, Darmaputri S, Sani AA, Roebiono PS, Fakhri D, Djer MM, Munasir ZM, Batubara JRL, Satroasmoro S et al: Oral Triiodothyronine Supplementation Decreases Low Cardiac Output Syndrome After Pediatric Cardiac Surgery. Pediatr Cardiol 2019, 40(6):1238-1246.

11. Portman MA, Slee A, Olson AK, Cohen G, Karl T, Tong E, Hastings L, Patel H, Reinhartz O, Mott AR et al: Triiodothyronine Supplementation in Infants and Children Undergoing Cardiopulmonary Bypass (TRICC): a multicenter placebo-controlled randomized trial: age analysis. Circulation 2010, 122(11 Suppl):S224-233.

12. Flores S, Loomba RS, Checchia PA, Graham EM, Bronicki RA: Thyroid Hormone (Triiodothyronine) Therapy in Children After Congenital Heart Surgery: A Meta-Analysis. Semin Thorac Cardiovasc Surg 2020, 32(1):87-95.

13. Guden M, Akpinar B, Saggbas E, Sanisoglu I, Cakali E, Bayindir O: Effects of intravenous triiodothyronine during coronary artery bypass surgery. Asian Cardiovasc Thorac Ann 2002, 10(3):219-222.

14. Choi YS, Shim JK, Song JW, Song Y, Yang SY, Kwak YL: Efficacy of perioperative oral triiodothyronine replacement therapy in patients undergoing off-pump coronary artery bypass grafting. $J$ Cardiothorac Vasc Anesth 2013, 27(6):1218-1223.

15. Yasar Z, Kirakli C, Cimen P, Ucar ZZ, Talay F, Tibet G: Is non-thyroidal illness syndrome a predictor for prolonged weaning in intubated chronic obstructive pulmonary disease patients? International journal of clinical and experimental medicine 2015, 8(6):10114-10121.

16. Datta $D$, Scalise $P$ : Hypothyroidism and failure to wean in patients receiving prolonged mechanical ventilation at a regional weaning center. Chest 2004, 126(4):1307-1312.

\section{Figures}


1896 patients receiced cardiac surgery

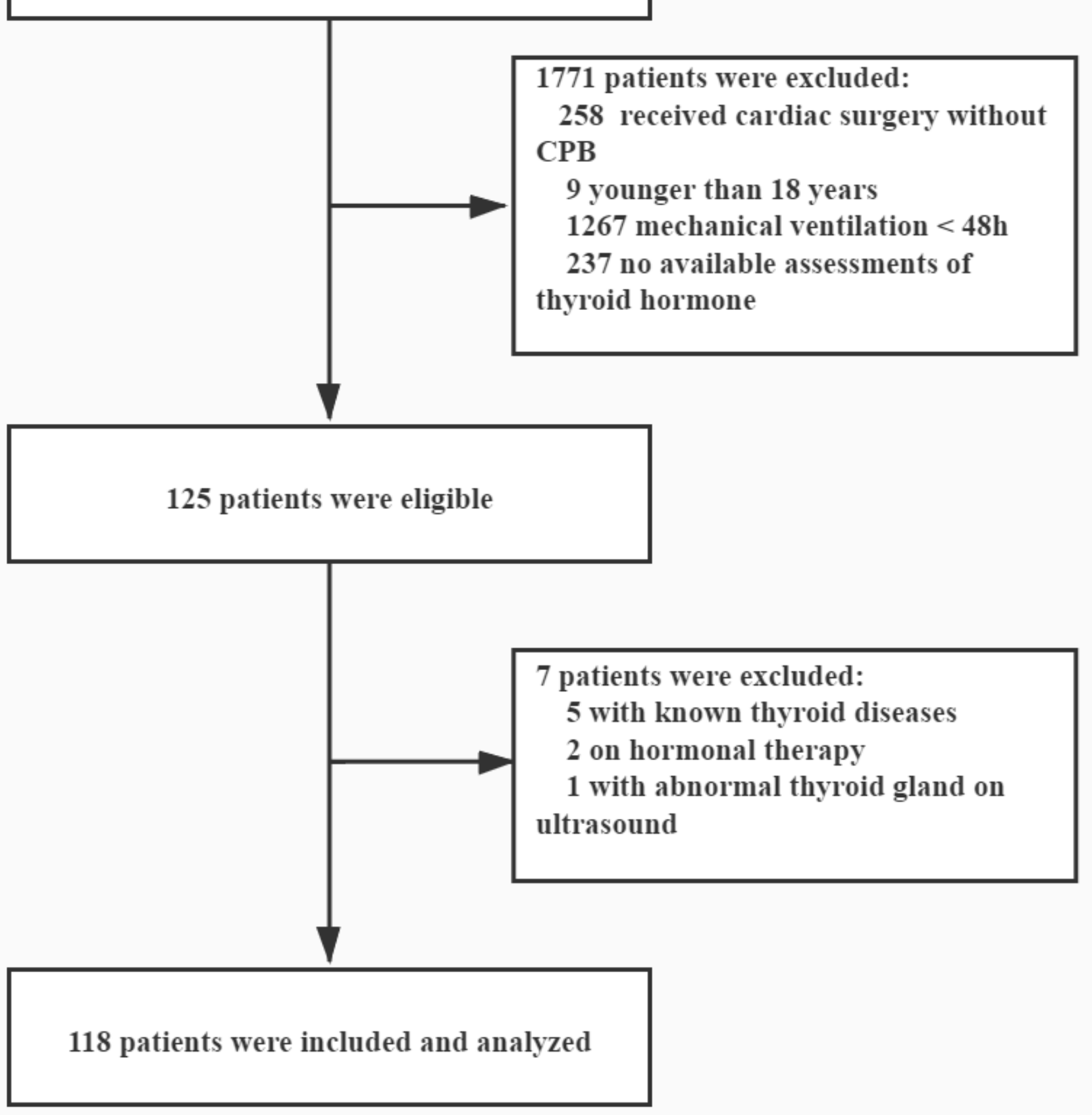

Figure 1

Screening of the study patients. 
A

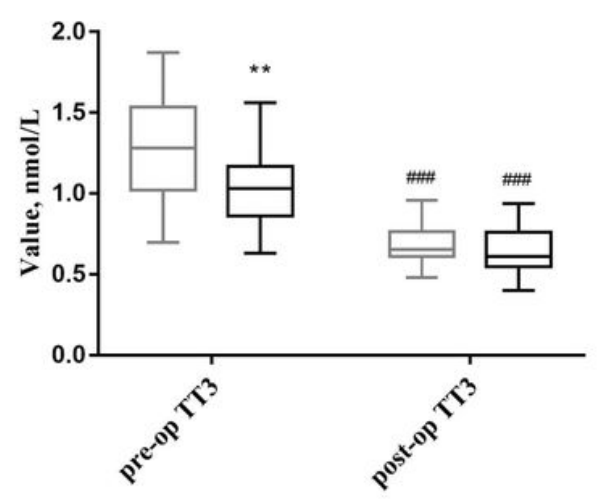

C

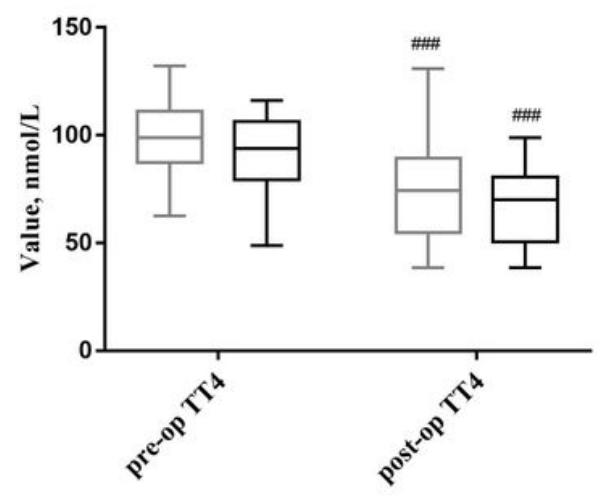

B
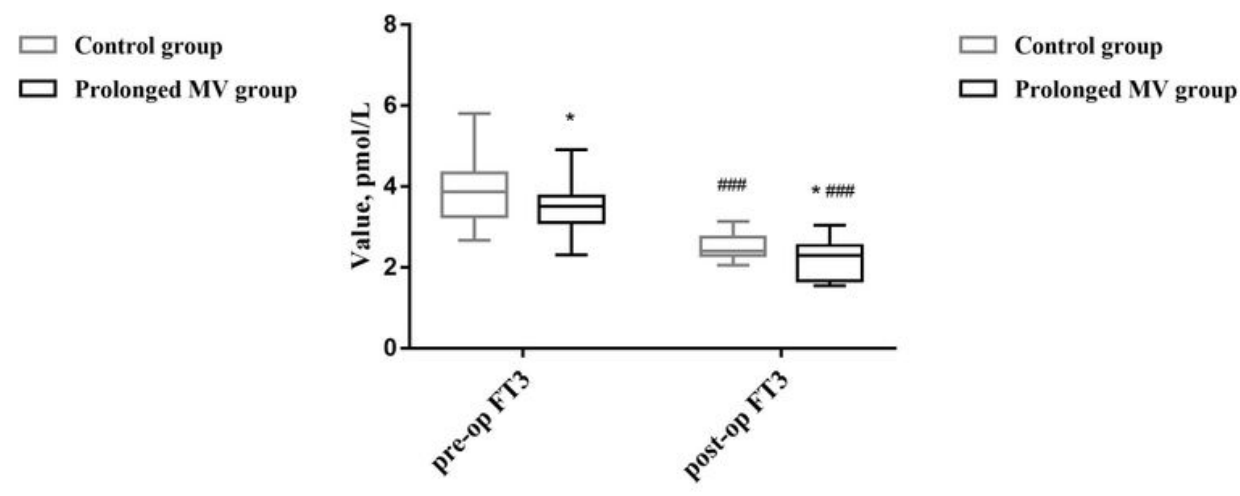

\section{D}

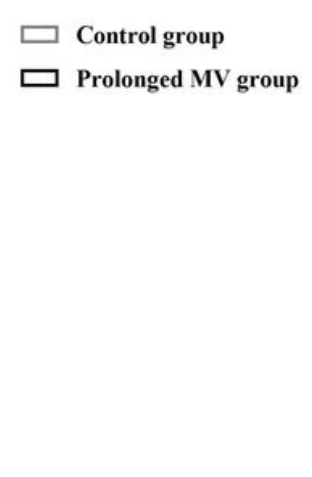

$\square$ Control group

$\square$ Prolonged MV group

\section{Figure 2}

Box-and-whisker plots for thyroid hormone before and after cardiac surgery in patients of control group and prolonged MV group. A. Serum level of TT3 before and after cardiac surgery in the patients of the two groups. B. Serum level of FT3 before and after cardiac surgery in the patients of the two groups. C. Serum level of TT4 before and after cardiac surgery in the patients of the two groups. D. Serum level of FT4 before and after cardiac surgery in the patients of the two groups. *: $P<0.05$ vs. Control group, $\star *$ : $P<0.01$ vs. Control group; \#: $P<0.05$ vs. pre-op, \#\#: $P<0.01$ vs. pre-op》\#\#\#: $P<0.001$ vs. pre-op. 